\title{
Devolution of Public Health care Services in Kenya and its Implication on Universal Health Coverage
}

\author{
Timothy C. Okech, $\mathrm{PhD}$ \\ Associate Professor of Economics, United States International University-Africa
}

\begin{abstract}
Quality and affordable health services at a health facility and access toward the same by those who need continue to be pursued by Kenya government as progress towards achieving Universal health coverage. The government has over the years endeavored to provide a strong, efficient and a well-run health system with sufficient capacity of well-trained, motivated health workers and a system for financing health services. This is evidenced in the various policies and strategies including devolution of public health care to county governance units. In the paper, an empirical analysis is undertaken to provide situational analysis on how these initiatives particularly has impacted on universal health coverage in terms of health equity concerns of access, quality of care, distribution of health resources including health workers, finance and infrastructure, among others. To accomplish this, both primary and secondary data were collected. Whereas secondary data was collected from published documents and reports, primary data was collected through in-depth interviews with key stakeholders. The analysis reveals government commitment towards universal coverage through increased revenue allocation in absolute terms, pooling of resources, investment in both health infrastructure and personnel over the years, that is, however uncoordinated and unplanned. Others findings include cases of health inequity in terms inadequate health facilities; lack of comprehensive investment plans; stock-outs of drugs and other medical supplies, inadequate skilled and skewed distribution of the health workers, catastrophic health spending, limited solidarity in financing of health care. Other equity concerns relate to inadequate and dilapidated health infrastructure, skewed distribution of health resources, disease burden, and differences in health outcomes across the country. Various recommendations are made including concerted efforts towards solidarity in health care financing, political will towards the development of a comprehensive health sector investment plan, revising and implementing the infrastructural norms and standards; fast tracking the enactment of Health Act; Procurement Bill for drugs and pharmaceutical supplies. Other recommendations include enforcement of standards in the public health sector with respect to infrastructure, human resource, skills and supplies, civic education for all for purposes of enforcement demand for quality care; and finally, enhance the pharmaceutical management information system for purposes of proving accurate and reliable evidence based information for estimation of Essential Medicines and Medical Supplies needs and well as enhancing quality assurance and quality control activities.
\end{abstract}

Keywords: Devolution, Social Solidarity, Health Equity, Universal coverage, Decentralization

I. INTRODUCTION

\subsection{Background}

Devolution is the statutory delegation of powers from the central government of a sovereign state to govern at a sub-national level, such as a regional or local level. It is a form of administrative decentralization or the transfer of authority and responsibility from central to lower levels of government for a range of public functions including health care (Williamson \& Mulaki, 2015). Devolved territories have the power to make legislation relevant to the area meaning that the units have clear and legally recognized geographical boundaries over which they exercise authority and within which they perform their functions in their respective jurisdictions. Worldwide, there has been a trend in the devolution of authority in healthcare whereby the authority that was often sitting with one central Ministry or Department of Health devolved over time (KPMG, 2015; Okech, 2016). When governments devolve functions, they transfer authority for decision-making, finance, and management to quasi-autonomous units with corporate status (World Bank, 2014). Depending upon the functions and authorities transferred, decentralization processes can involve one or more categories (ibid).

In Kenya, following the promulgation of the new constitution in 2010, a devolved system of governance with two levels of government - National and County government was created (Okech \& Lelegwe, 2016). At national level, health leadership is provided by the Ministry of Health (MOH) whose key mandates 
include development of national policy; provision of technical support at all levels; monitoring quality and standards in health services provision. Others include provision of guidelines on tariffs for health services, conducting studies required for administrative or management purposes (ibid). The Ministry is also mandated with the development of national policy that guides the recruitment, placement, training and remuneration of all health workers in the country; monitoring quality and standards in health services provision, and the charges for the various services by health care providers. Provision of necessary legal framework for ensuring a comprehensive and people driven health care delivery is also the responsibility of the Ministry of Health (GoK, 2010; Okech, 2016). County governments, on the other hand, are responsible for county legislation; establishment and staffing of a public service; provision of infrastructure and equipment for health facilities such as new wards, ambulances and recruitment and management of health workers (GoK, 2010; Okech \& Lelegwe, 2016). Though the two levels of government are autonomous in principle, they are interdependent and conduct business on the basis of consultation and cooperation (World Bank, 2014). In the constitution, the government provides for the right to access emergency health services by all including children and persons living with disabilities. This has been argued is the government's concerted efforts and commitment towards universal health coverage (UHC) \{Okech, 2016\}.

UHC is defined as ensuring that all people use the promotive, preventive, curative, rehabilitative and palliative health services they need and, of sufficient quality to be effective, while also ensuring that the use of these services does not expose the user to financial hardship (World Health Organization, 2010). Three related objectives are singled out by World Health Organization (WHO) in the process of realizing UHC. These include equity in access to health services so that those who need the services should get them irrespective of their ability to pay; quality of health services should be good enough to improve the health of those receiving; and, finally financial risk protection which aims at ensuring that the cost of health care does not put people at risk of financial hardship. According to WHO, four core elements are necessary in the realization of universal coverage: i) a strong, efficient, well-run health system; ii) a system for financing health services; iii) access to essential medicines and technologies; and finally a sufficient capacity of well-trained, motivated health workers (WHO, 2010; Okech \& Lelegwe, 2016).

In Kenya, the national government in 2013 abolished user fees at primary health care facilities and introduced free maternal health care services in public health facilities. Similarly in the draft Health Bill of 2015, the government declared access to reproductive health and emergency medical treatment as a right by all persons (Okech \& Lelegwe, 2016). Other UHC initiatives are emphasized in the Health Financing Strategy, wherein the government emphasized social health protection to all Kenyans; fast tracking the provisions of the constitution is the government's identification and settlement on National Health Insurance Fund (NHIF) as a vehicle for social protection founded on complementary principles of social health insurance and tax financing (NHIF, 2015; Okech, 2016; Okech \& Lelegwe, 2016). The Kenya government has also continued to fast track various initiatives including developing and piloting a national referral strategy, strengthening of private public partnership (PPP) such as the "Beyond Zero" campaign, Linda Mama program, health insurance subsidies targeting indigents. Considering the government's efforts towards universal health coverage, the paper aimed at undertaking situational analysis of health equity issues emanating from the efforts by focusing on access to quality care, availability of drugs and other medical supplies, distribution of health resources especially infrastructure, finance and personnel.

\section{METHODOLOGY}

Both primary and secondary data were collected regarding identified equity issues. In terms of secondary data, a review of relevant literature on key policy initiatives aimed at universal coverage and how they have impacted on health equity was undertaken. This information was obtained from various sources including Ministry of Health official documents such as the draft Kenya National Health Sector Strategic Plan (KHSSP) III, draft Health Policy Framework, 2012 - 2030, draft Health Care Financing Strategy, and National government documents such as Vision 2030, Medium Term Expenditure Framework (MTEF) paper, National Hospital Insurance fund documents (Manuals, strategic plans, operational plans, among others), the Constitution and the Draft Health Bill, 2015. Additional data was also collected from relevant commissioned studies such as Kenya Health Labour Market Assessment report, status of the Managed Equipment Scheme, journal articles, publication, and conference papers, among others. This was supported by in-depth interviews with key stakeholders in the sector at both National level and county levels. 


\section{HEALTH INDICATORS}

The Government of Kenya has remained committed to the improvement of the health outcomes in the country. The government has taken important steps towards this goal over the years, emphasizing that the provision of health services should meet the basic needs of the population and be geared towards providing health services within easy reach of Kenyans (Okech \& Lelegwe, 2016; Okech, 2016). Considerable emphases have been put towards preventive, promotive and rehabilitative health services as well as curative services. The initiatives have contributed towards improvements in the health indicators as shown in table 1.1.

\section{Table 1: Health Indicators}

\begin{tabular}{|lc|}
\hline Maternal deaths per 100,000 live births & 362 \\
Delivered in a health facility & $61 \%$ \\
Full vaccination & $79 \%$ \\
Stunted growth (too short for age) - \% under 5 years & $26 \%$ \\
Use of ITN - \% & $59 \%$ \\
HIV testing - \% women & $83 \%$ \\
HIV testing - \% men & $71 \%$ \\
Neonatal mortality -- per 1,000 live births & 22 \\
Access to delivery by skilled health workers - $\%$ & $62 \%$ \\
Post natal care - \%- & $53 \%$ \\
Nutrition status- $\%$ - under 5 years $\quad$ & $4 \%$ \\
$\quad$ Wasted & $11 \%$ \\
$\quad$ Underweight & $4 \%$ \\
Overweight & $6.1 \%$ \\
Malaria Prevalence & $6 \%$ \\
\hline
\end{tabular}

Source: KDHS, 2014; PRB, 2015

Although the health indicators have improved over time, most still fall below the then 2015 Millennium Development Goals (MDGs). Similarly, the indicators continue to lag behind those of the rest of world including sub-Saharan Africa (SSA) [see appendix two in the appendices]. Notable indicators of concern relate to infant mortality rate, under-five mortality rate and maternal deaths, despite significant progress in Contraceptive prevalence rate for married women.

\section{GOVERNANCE OF PUBIC HEALTH CARE IN KENYA}

\subsection{Historical Analysis of Universal Health Coverage ${ }^{1}$}

Upon attaining independence in 1963, the Government recognized the pivotal role of health towards socioeconomic development and embarked on wider policy reforms aimed at enhancing access to quality and affordable health care by Kenyans that then favored the white minority. The government set to put in place policy framework towards the realization of this goal by focusing on the provision of primary health care (PHC) and training of various cadres skilled health workers. Also considered was putting in place health infrastructure necessary for providing comprehensive health care (GoK, 2010). This in the process contributed towards improvements in health indicators such as infant and child mortality, and life expectancy. For instance, life expectancy improved from 46.4 in the 1960s to 58.7 in 2010, while infant mortality rate reduced from 118.6 to

${ }^{1}$ This sub-section borrows from Okech \& Lelegwe, 2016 
42.2 per 1,000 births over the same period. Table 2 provides a summary of key health indicators between $1960 \mathrm{~s}$ and 2010 .

Table 2: Key Health Indicators over time

\begin{tabular}{|l|l|l|l|l|l|}
\hline Indicator/Period & 1960 & 1970 & 1980 & 1990 & 2010 \\
\hline Infant mortality rate & 118.6 & 91.3 & 69.4 & 65.8 & 42.4 \\
\hline Life expectancy & 46.4 & 52.2 & 57.8 & 50.8 & 58.7 \\
\hline Fertility rate & 7.9 & 8.1 & 7.5 & 6.0 & 4.6 \\
\hline
\end{tabular}

Source: KDHS, 2015

In the recognition of the role of a well run health system and financing play in contributing towards universal coverage, the government developed the Health Policy Framework and a five-year National Health Sector Strategic Plan (NHSSP) of 1999-2004 wherein targets and processes driving the health sector development, as well as healthcare service delivery were emphasized. The reforms relating to the way the healthcare services were not only reorganized but also financed, delivered and evaluated. Equitable allocation of government resources to reduce disparities in health status and increased cost-effectiveness and efficiency of resource allocation and use were imputed. Others included enhanced regulatory role of the government in health care provision; provision of conducive environment for the involvement of both private and community in health care; and increase and diversify per capita financial flows to the health sector. All these measures, can be argued were key ingredients necessary in universal coverage.

In terms of financing, statistics show that the government is allocating less than four percent of its annual budget on the financing of heath care with allocation estimated at $3.2 \%, 2.7 \%, 2.3 \%$ and $2.5 \%$ in 2014/15, 2015/16, 2016/17 and 2017/2018, respectively. This compares to the Abuja declaration of 2001 where African governments including Kenya to allocate at least 15 percent of their respective annual budget to the health sector. The ruling coalition reiterated in its manifesto to increase the allocation from 6\% in 2012/2013 to $15 \%$ during the 2013 campaigns. Achieving the target would reflect government's commitment to some degree of health prioritization in its expenditure. There also exist high out of pocket (OOP) spending and high levels of donor support in favor of one donor with a significant percentage considered off-budget. The skewed financing not only raises long term sustainability, but also pause a challenge on coordinated planning for improved equity in the distribution of resources and access to the necessary services. It is estimated that, about $15 \%$ of Kenyans spent more than $40 \%$ of non-food expenditure on health care. This if not carefully addressed could lead to catastrophic health spending and in the process impoverish the already impoverished households (P4H, 2014). If transportation costs, accommodation and food for those who accompany the patient are considered the percentage could be much higher. Considering that health is not only a consumer good but also an investment, households have devised various coping mechanisms which in the process impact on them negatively. These include mortgaging their limited assets such as land, household items or seek alternative health care or simply opt to stay at home.

The share of government spending in the government budget depicts general under-financing of publicly provided for services, even though for some services especially for non-communicable diseases, the gap is bridged by donors (Bultman, 2014; $\mathrm{P} 4 \mathrm{H}, 2014$ ). This according to $\mathrm{P} 4 \mathrm{H}$ is related to the co-existence of several different coverage schemes with the main ones being the GOK free-care initiatives at primary health care facilities and free maternal care at higher levels, GOK subsidized access for other care at referral levels, the NHIF, as well as Private Health Insurance (PHI). Devolution according to P4H adds to the complexity, as counties are now expected to finance health service provision for health care services from their block grant allocation. Though the national government is committed towards free maternal health care services, counties have raised concerns over delays by national government in releasing the conditional grant.

The existence of fragmented financing of the health system creates obstacles for an integrated service provision which further worsens the situation (P4H, 2014; Okech, 2016). Fragmented financing mechanisms are likely to create incentives working against this principle. Ordinarily, patients have an incentive to seek care where they are covered against the costs of treatment. Where hospital treatment is covered, patients may bypass primary facilities where adequate treatment can be provided at the lowest possible costs (P4H, 2014). Whereas some areas in need may fall between the gaps of different funders (especially if the areas are poor and providers are motivated by profits), some may be oversupplied with care, especially high-cost technologies. This does not only reduce available funding for investments into disadvantaged areas, but also increases recurrent costs. This 
is especially the case for diagnostic devices, where providers can induce demand while quality of care may suffer notwithstanding the expected disparities in terms of access (P4H, 2014).

The Kenya Health Policy Framework Implementation Action Plan was developed, followed by the establishment of the Health Sector Reform Secretariat (HSRS) to spearhead the implementation of the health care financing policies in coordinated manner. At the same time, a rationalization programme within the Ministry was also initiated aimed at responding to the financing of the public health sector in order to enhance access to quality care amongst the poor and other vulnerables. Over the same period, the National Hospital Insurance Fund Act was repealed for purposes of enhancing financial protection and broadening the coverage, while enhancing governance of the institution. NHIF service coverage however, was not expanded at that time while the envisaged benefit package remained narrow (Okech, 2014; Okech \& Lelegwe, 2016).

The government launched the country's development blue print - "Vision 2030" in 2007 where the role the social sector (health and education) was recognized in driving the country towards a competitive environment and a medium income country (GoK, 2007). This was to be realized through the provision of robust health infrastructure in terms of equipment, strengthening health service delivery, development of risk pooling financing mechanisms, while at the same time ensure AID effectiveness and harnessing social solidarity in the country. In the Health Financing Strategy of 2010, the government further appeared committed towards universal health coverage by emphasizing social health protection to all Kenyans by introducing social solidarity mechanisms for purposes of financial protection of the poor and other vulnerable groups. In order to achieve the set objectives, the government reiterated its commitment to amend the NHIF Act for purposes of enhancing access, and broadening benefit package.

The government abolished user fees at primary health care facilities and introduced free maternal health care services in public health facilities in 2013. Currently this is being implemented under Linda Mama Programme by NHIF. The effect of this on access to health by the poor depended first on whether health centers and dispensaries (and not hospitals) could deliver the bulk of the primary interventions related to KEPH given that these facilities act as the entry point for care. Secondly, the overall compliance with the policy across facilities has been a concern with many expectant mothers being turned way due delays in the reimbursement by NHIF. The third concern has been the transfer of patients from private facilities (not covered by part of the policy, or less likely to implement) to public or non-profit facilities (covered by the policy, more likely to implement).

Though the policy is considered populist and meant to enhance access to quality care, by the poor and other vulnerable groups, its implementation has been argued is technically unattainable. For instance, following the policy pronouncement, cases of delays in the disbursement of funds to counties continue to be experienced with the National government citing the failure of the integrated financial management information system (ifmis) - government integrated procurement and payment system. Similarly, cases where patients have had to pay directly for the services that would otherwise be provided freely, have been witnessed in various public facilities, with health workers complaining of lack of necessary health infrastructure, drugs and other medical supplies. Other concerns include stock outs of drugs and other medical supplies, poor maintenance of equipment, lack of transport, and medical facilities. It is worth noting that these factors have contributed towards the industrial action that doctors have resorted to since early December 2016. The resulting outcomes which are yet to be empirically evaluated are likely to contradict the very equity issues that were to be addressed under the policy initiatives.

Other initiatives include public private partnerships (PPP) such as "Beyond Zero Tolerance" campaign for expectant mothers, children and breast cancer are some of the latest efforts towards UHC. This has seen in the recent past many stakeholders pull resources towards the initiatives although there are still no reliable statistics to inform policy dialogue on the effect of the initiative. Whereas this is positive step in the right direction, there is lack of policy to support the initiative to ensure sustainability in the event of political regime change, with health workers raising concerns that this is creating a parallel health system that lacked technical and necessary legal and operational policies and the input of key stakeholders including the service providers especially the health workers. Finally, recently the government identified NHIF as official vehicle for the successful implementation of universal health coverage for the country (NHIF, 2015). The national scheme envisages universal coverage in which both in patient and out-patient services for members are catered for (Okech \& Lelegwe, 2016). A number of issues continue to be experienced including patients being turned away in facilities thereby not accessing the services, while others end up paying direct to the service providers for the services which otherwise are free. In the process this would contribute towards catastrophic spending thereby negating one of the core elements of universal health coverage of financial risk protection. 


\subsection{Devolution and Health Equity}

In the new constitution, the government provided the necessary legal framework for ensuring a comprehensive and people driven health care delivery aimed at enhancing access to quality and affordable health care. The Constitution introduced a devolved system of governance with two tier government systems namely the County and National government with the goal of enhancing utilization and geographical access to quality care by all Kenyans. The constitution further provides for the right to access health care including emergency health services by all including children and persons living with disabilities as key areas of focus in health services delivery (Okech, 2016). Devolution however, represented a major shift from the system that existed before such that many stakeholders or actors had little information about their roles and responsibilities during devolution. To forestall the process, Kenyan government brought together health system actors in various forums from mid 2012 to the end of the first quarter of 2013 to develop a shared understanding of devolution, discuss common concerns, and find consensus on implementation (Williamson \& Mulaki, 2015).

With devolution, County governments were introduced charged with the responsibility of planning, implementation, capacity development among others in the health sector. These new roles required the inclusion of county-level stakeholders, and the Ministry of Devolution and Planning promoted a new coordination mechanism for the two levels of government to discuss common issues namely the Health Sector Intergovernmental Forum (HSIF). The HSIFs since then with donor support developed human resources, pharmaceutical, and financial management plans, to ensure that county level health services are not interrupted. Within the devolved framework, Transition to Devolved Government Act (2012) was enacted with the objective of providing a three-year transition period to devolve government services-including capacity assessments and system audits however, political pressures derailed these plans. Once governors and county assemblies were elected in March 2013, they petitioned the president to devolve authority and resources to the counties as quickly as possible (Commission for the Implementation of the Constitution, 2014). Services and resources were eventually devolved, while a number of outstanding questions and concerns remained for the Kenyan health system. Among these were health infrastructure and personnel, resource envelop for the county, procurement of health sector commodities (that saw the Kenya Medical Supplies Agency (KEMSA) lose its monopoly over health sector commodity procurement) [Williamson \& Mulaki, 2016; Okech, 2016].

Unsurprisingly, significant capacity gaps continue to be witnessed within county political and management structures given that a few possessed the administrative capability to absorb the available funding or plan for the use. This in the process impacted negatively on the allocation of resources towards health sector with a significant percentage being allocated towards payment of salaries and wages, leaving an insignificant percentage for curative and preventive health care services. Although the national government was concerned about these capacity gaps, it had not however, outlined training and mentoring plans for the counties, as it expected to use the full three-year transition period originally allowed by law to sort them out. Further, the new constitution did not specify whether national or county governments would manage the then Provincial General Hospitals (PGHs) or how counties would procure pharmaceutical products. In keeping with earlier requests for more resources and authority, county governments wanted to take over both the control of PGHs and procurement flexibility.

The national government on the hand wanted to keep PGHs under its control by designating them as national referral hospitals, with KEMSA as the sole procurement option for counties (Williamson \& Mulaki, 2016). As a result of this ambiguity and political maneuvering, the Transition Authority negotiated with the Council of Governors to transfer PGH management to county governments, with directed funding from the national governments to ensure service continuity. Negotiations between the $\mathrm{MOH}$ and county governments also yielded a compromise on pharmaceutical procurement where all the counties agreed to procure pharmaceuticals from KEMSA (Williamson \& Mulaki, 2015). Following this agreement, cases of stock-outs of drugs and pharmaceutical supplies continue to be experienced with some suppliers reluctant to supply the same to counties citing delays in payments for the supplies.

Counties further sought to expand the scope of resources transferred from the national government, increase their authority over services, and reduce national government restrictions. The national government however, fought to retain centralized control. Although some issues have already been resolved, major human resource management questions remain, such as personnel transfers, salary payment, and terms of service including remuneration, promotion and support for continuous medical education. These questions highlight ongoing conflicts among health workers that seen doctors resorting to industrial action thereby paralyzing health care services in all public health facilities countrywide. Whereas, counties have sought authority to hire, release, and set standards for health workers, in order to maximize both power and autonomy, doctors have on the other 
hand sought better terms of service including timely payment of enhanced salaries, opportunities for post graduate training, improved health infrastructure, among other concerns. In a way doctors have a valid concern since according to WHO (2010), a strong, efficient, well-run health system with a sufficient capacity of welltrained, motivated health workers are critical $n$ the realization of Universal coverage. 


\subsection{Analysis key Universal Health Coverage Program}

One of the key UHC programs that the government is currently implementing if free maternal health program that was initiated and implemented in 2013. In between 2013 and the end of 2016, slightly over 2.3 million women had benefited from the government's Free maternity Programme at a cost of estimated at Ksh 12 billon. These women got access to theatre and midwife counseling and family planning services, medication as well as access to family planning options. This saw deliveries increasing from 461,995 in 2012/13 to 627,487. This compares to 811,655 in 20142015 and 911,959 in 2015/16. In 2016/17 the government set aside Ksh 6 billion towards the programme. Reports however show that there is change in tack as the programme is earmarked to be implemented by National Hospital Insurance Fund instead of direct reimbursements to health facilities through counties for the number of deliveries reported. This new phase code-named Linda Mama Programme was set up to rope in more women and children from poor and under-privileged backgrounds. Under this package, the government is expected to pay Ksh 6,000 per woman covered, while expectant mothers are entitled to at least four antenatal delivery and postnatal check-ups.

There is no doubt that this programme has significantly reduced maternal mortality, however, this war has not yet been won yet as nearly 14 women die from pregnancy related causes daily according to statistics from the Ministry of Health. The deaths are a result of severe bleeding, infection, hypertensive disorders, obstructed labour, malaria, diabetes, hepatitis and anemia. This is attributed to shortage of funds, lack of equipment and drugs, and delays in government reimbursing health facilities that offer free maternity services. On the other hand cases of push and pull between counties and national government for control of the billions of shillings set aside continue to be experienced an absurd situation that has affected health equity negatively. It is estimated that the Ministry of Health is yet to pay Ksh. 1.4 billion (at the current exchange rate of Ksh 100 for USD 1, this translates to USD 14 million) from the year 2014/15 financial year. Reports show that the money was used to buy 100 containers which according to the Ministry were to be used to provide mobile clinical services in slums. One year since the containers were procured and paid for, they remain in the government yard unutilized.

Similarly, cases where expectant mothers have been asked to bring their own gloves, cotton wool, and other medical items before delivery have been reported in some counties, with a number opting to deliver. The situation is exacerbated by inadequacy of trained staff, low staff morale, distance to a facility with necessary facilities. This continues to be experienced despite the government commitment to enhance the same in the Kenya Child and Adolescent Health Investment Framework. Currently, there are about 5000 facilities that offer maternity services which a few facilities especially dispensaries recording insignificant number of births per month, yet they have a team of nurses, while in other regions there is shortage of such skills. This raises equity issues with regard to equitable distribution of qualified health workers and availability of health infrastructure and equipment, which in the process affects access to quality health care by the poor who unfortunately are the majority in the country. For purposes of equity one would expect appropriate equipment and personnel for the maximum benefits to mothers and the newborns. Reports show that in some of the county referral facility, the conditional grant for the program has never been received four years since the program was launched and implemented, neither has NHIF remitted the deductions that the insurance should cater for. This has made the facility to accrue debt estimated at US 1 million from suppliers of consumables including food and pharmaceutical supplies.

It is estimated that the cost of running a level five hospital (mostly county facilities) which ideally should serve about one million people, is Ksh. 1.4 million annually excluding medicine or reagents for laboratories (Commission of Revenue Allocation, 2015). In many facilities, it is not unusual to find patients at the casualty area being asked to purchase emergency medication to stop blood loss or to buy surgical necessities. Though facilities continue to experience various hiccups as a result of devolution such as perennial strikes by medical staff, shortage of funds (making counties to seek bank overdrafts), leakage of revenue from the system, dilapidated equipment, shortage of drugs and other necessary pharmaceutical supplies remain a key challenge. The tussle between the Kenya Medical Supplies Authority (KEMSA) and the county governments over the procurement off drugs and other medical supplies was a key concern. As the tussle continues, great uncertainty over procurement of medical supplies and technologies within the national health care system has continued to affect service delivery. 


\section{PUBLIC HEALTH CARE SERVICES DELIVERY AND UNIVERSAL HEALTH COVERAGE}

In the provision of health care, well trained and motivated health work force is important. Equally important is availability and functionality of health infrastructure and equipment as well as medical and pharmaceutical supplies. In the sub-section, an analysis of these key ingredients is provided.

\subsection{Health Personnel and Training}

Availability and comprehensiveness of health services offered at a health facility depends partially on the number and quality of health workers at facilities and the appropriate health infrastructure as well as a system of financing the services. Similarly, a healthy population plays a critical role in boosting economic growth, poverty reduction and realization of social, economic and political goals (GoK, 2007; Sohnen et al., 2015). Key areas of focus for Kenya's health sector, as laid out in the Kenya Vision 2030 document, are access, quality, capacity and institutional development. Achieving these healthcare goals depends greatly on the financing mechanisms, having the necessary human resources for health and infrastructure to deliver the healthcare services. Table A1 in the appendices provides a summary of the available health workers in the entire health sector (both in public and private sector).

Statistics show that there is one (1) doctor for ten thousand $(10,000)$ persons with one nurse per six hundred and fifty persons. This compares with WHO recommendation of one doctor for 1,000 persons and one nurse per 280 persons. Reports also show that about a third of the doctors and nurses are in the private sector. Overall, the country's health sector still faces significant human resource shortages, in spite of the investments the government has made over the years since independent and following the devolution of health services $(\mathrm{MoH}, 2015)$. Measured against the WHO's recommended staffing norms and standards, Kenya has a shortage of 83,000 doctors. Most acute gaps based on numbers required, and proportional gaps are for general clinical officers, public health officers and technicians, enrolled nurses, pharmaceutical technologists and patient attendants (Kenya Health Labor Market Assessment Report, 2015). Reports further show that more than 5,000 Kenyan trained doctors have emigrated for reasons attributable to poor pay and 3,000 more have left health to join others sectors, leaving 3,440 doctors for the nearly 46 million Kenyans who undoubtedly depend on national and county hospitals (Kenya Health Labor Market Assessment Report of 2015).

Majority of the doctors left the public practice following the implementation of the new constitution in 2013, where health services were devolved to county governments. This was attributed lack of policy direction on human resources' practices such as recruitment and retention, promotion, delayed salaries, remuneration, opportunities for continuous medical education, among others (Okech, 2016). Like most countries in Africa, the shortage of healthcare workers is not unique to Kenya. Indeed, Kenya is one of the countries identified by the WHO as having a "critical shortage" of healthcare workers. The WHO has set a minimum threshold of 23 doctors, nurses and midwives per population of 10,000 as necessary for the delivery of essential child and maternal health services. Kenya's most recent ratio stands at 13 per 10000 . This shortage is markedly worse in the rural areas where, as noted in a recent study by Transparency International, under-staffing levels of between 50 and 80 percent were documented at provincial and rural health facilities (Transparency International, 2015). Cases of significant gaps in essential specialized care capacity exists forcing individuals to seek these services abroad again impacting the pursuit of financial protection.

Doctors according to KMPP\&DU are poorly paid and the end result is that most doctors only work for the government to fulfill their internship requirements. This is partially attributed to availability of opportunities for continuous medical education for career growth and advancement in skills, and inadequate and dilapidated health infrastructure. Other challenges include perceived mismanagement of human resources at the county level. This has in the process affected health equity by Kenyans in terms of access to quality health care. At the time of the study doctors (medical doctors, pharmacists and dentists) were on strike for more than two months paralyzing public health sector in the country. At one time this split over to private sector where the doctors joined their colleagues in solidarity. The situation has subjected many patients to more suffering. On the positive side, hard to reach counties are committed towards investing in human resources for health while at the same time attract and retain them in services and have initiated various incentives to attract and retain health workers such as performance best financing, risk allowance, provision of air ticket and bonuses, among others. Planning and development of human resources for health must be immediate action by the Ministry beyond the political poetry of equipping county hospitals that doctors seem to have long deserted. 
In both the Ministry's published norms guidelines, and in its actual practice, the tendency has been to allocate more budget for the middle categories requiring three years of training, exemplified by registered (diploma-level) nurses, and significantly fewer jobs for less costly occupational categories such as enrolled (certificate-level) nurses (two years of training), and nursing assistants and patient attendants (one year of training). This trend resonates with global trend towards professionalization of nursing, including higher levels of training and education. Also, while some healthcare professionals flow out to join teaching and/or research, others upgrade to special consultants and/or venture into administration, business, teaching, or Information and Communications Technology (ICT). Although the occupational structure of each facility will depend on the actual capacities of the clinical staff and the needs of the patient population served, at the aggregate national level, one would expect a country with a shortage of training capacity and an excess supply of less-educated workforce to have a health workforce that exhibits a pyramid structure (Sohnen et al., 2015).

Training and development of the Human Resources for Health (HRH) is one of the core elements towards the realization of universal health coverage. As indicated in Table 3.1 in the appendices, there are less than 1,000 specialists in the public sector indicating a shortage of these cadres of health workers. It is thus necessary that the shortage of specialists of various cadres in various fields be addressed through planned and prioritized training. It is estimated that the Ministry of Health currently receive slightly less than Ksh. 100 million yearly compared to bout Ksh. 400 million that is required to invest in human resources for Health. This has partly contributed towards inability in providing specialized quality services. The situation is made worse by investment in infrastructure for use by the specialists in the provision of care. Human resource investments need to be designed to address the availability of appropriate and equitably distributed health workers, attraction and retention of required health workers, while improving the institutional and health worker performance

\subsection{Health Infrastructure}

To realize universal coverage, a strong, efficient, well-run health system is necessary (WHO, 2010). This in turn requires a robust health infrastructure in terms physical infrastructure, medical equipment, communication and ICT, Transportation. Kenya's health care provision and implementation infrastructure include the national teaching hospital, provincial hospitals, district and sub-district hospitals, health centers, and dispensaries, as well as a host of other operators within the private, non-governmental, and traditional/informal sectors. The system is a hierarchical-pyramidal organization comprising five levels, the lowest being the village dispensary with Kenyatta National Hospital $(\mathrm{KNH})$ at the apex. The health sector requires establishment of an effective organization and management system to deliver on the KEPH.

There is wide range of health facilities distributed countrywide. Majority of the facilities have very old and dilapidated infrastructure constructed $\mathrm{n}$ the first quarter of $20^{\text {th }}$ Century. The situation was made worse with upgrading of lower tier facilities to high level with many not capable of offering comprehensive package for primary health care. Still, most of them are not do not conform to required norms and standards with respect to health resources especially human resources, infrastructure and equipment. Also, the facility investments is not matched with other investments (HRH, commodities, etc), leading affecting functionality after completion of investments (Musymi, 2012; GoK, 2015; Okech, 2016). Similarly, there is limited investment in maintenance of physical infrastructure although investments in medical equipment are ongoing in selected hospitals. It is estimated that over two-hundred model health centres were either constructed or refurbished while over eighty hospitals are at various stages of completion. Following the devolution of health care, forty-seven hospitals were upgraded to county hospitals (level 5) which means that a number of hospitals need to be constructed to significantly improve access to each level healthcare.

In terms of ambulances, reports show that purchase of ambulances is ongoing, at hospitals, and model health centres though there still exist significant gaps in utility vehicle availability (some ambulances also used as utility vehicles as a result) [GoK, 2015]. The ministry and the counties re however, undertaking some measures to enhance transport possibilities in the sector such as outsourcing of certain activities to the private sector, like courier companies to collect/deliver stocks/specimens, car hire for referral in rural areas with appropriate reimbursement and ambulances for bigger hospitals (Okech, 2016). Accessibility to these health facilities (if one uses a $5 \mathrm{~km}$ radius as a yardstick) is estimated at 52 per cent (Kenya Integrated Budget Household Survey, 2006) nationally (Musyimi, 2012; GoK, 2015).

It is estimated that the current available equipment falls short of the required numbers, while of those available, about 50\% is too old to pass required standards and that maintenance of equipment has been inadequate $(\mathrm{MoH}, 2015)$. This exist despite the critical role that availability and functionality that equipment 
play. Distribution of health infrastructure remains skewed, with some areas of the county facing significant gaps, while others have surplus numbers coupled with $(\mathrm{MoH}, 2015)$. Cases where for instance specialized doctors complained of underutilization of their skills have been experienced with many opting to join private practice or resigning to pursue further studies. If the situation is not addressed, in the end, patients are likely to be left with no option but to either seek services of less qualified health personnel or providers or alternative health care services whose quality may not be guaranteed. Some of these challenges are currently being addressed, managed equipment scheme, construction of teaching referral hospitals in most of the counties.

Currently, a number of health facilities have acquired specialized machines and equipment through the National government's Managed Equipment Scheme (MES). Whereas this initiative is a move towards the realization of UHC, reports show that the equipment is working less than fifteen percent of the forty-seven counties. Cases of a number lying idle and gathering dust, despite costing the county government millions were witnessed in many counties despite counties paying lots of money every month. The gloomy situation has been attributed to lack of necessary personnel to operate the machines and equipment as well as lack of proper infrastructure for their installation.

\subsection{Medical and Pharmaceutical Supplies}

Supplies of medicines and medical supplies are vital inputs of medical care. To maintain a regular supply of these inputs, effective public commodity supply management is important. Currently, supply of essential medicines and non-pharmaceuticals is inadequate due to insufficient funds (Musymi, 2012; GoK, 2015). In the end, public health facilities have to undertake own purchases using user fees revenues, which however, not sustainable. Similarly, patients are in the process forced pay directly from the pocket, resulting in poor patient outcomes and inappropriate medicine use such as under- dosage and drug resistance. Reports show that the Kenya Essential Medicines list (KEML) is not fully adhered to with respect to supply of medicines in leading to a mismatch between the medicines supplied and the medicine needs for each level of care. As a result, cases of over and under stocking of drugs and pharmaceutical supplies in many facilities continue to be experienced. In the end, the medicine needs of the Kenyan population are not met (Musyimi, 2012; MoH, 2015).

It terms of funding, it is estimated that the Ministry receives only half of the required funds for pharmaceutical and non-pharmaceuticals supplies. The situation is worse for the supplies funded by development partners such as ARVs. This therefore implies that with the continued decline in donor funding, access to such supplies by those already on ARVs and new infections may be impacted negatively. Based on WHO estimates, about US\$1.5-2 per capita is required to provide essential medicines in a basic health care package. Currently the $\mathrm{MOH}$ allocation is estimated at USD 1.1 per capita translating to 2 billons annually which is however not sufficient (GoK, 2015). Funding for essential stationery and devices for drug administration such as treatment sheets prescriptions, dispensing bottles and labels, among others is also inadequate. As a result medicine administration is not optimal with the consequent risk of poor health outcomes. Current evidence shows that up to $30 \%$ of medicines in Kenya are counterfeit (Musyimi, 2012). This in the process has contributed towards increased morbidity and mortality and increased healthcare costs that ultimately reduce the performance of the health system.

\section{CONCLUSION}

Realization of UHC requires a strong, efficient, well-run health system in addition to a sufficient capacity of well-trained, motivated health work force. A healthy population plays a critical role in economic growth, poverty reduction and realization of social, economic and political goals (GoK, 2007; Sohnen et al., 2015; Okech, 2016). The government of Kenya has thus over the years initiated policies and strategies all aimed at realizing this, an indication of government's commitment and political will towards aimed at health equity. Health equity however, requires well-trained, motivated health personnel with the necessary health infrastructure and commodities. The study reveals significant gaps in health infrastructure especially specialized medical equipment, existence of dilapidated infrastructure, and demoralized health workers at both county and national government. There are also significant gaps in a number of key health personnel with a number opting to joining private practice or changing career altogether.

There are also concerns that many primary care facilities may not be offering comprehensive package of primary care services and that facility investments are not matched with other investments, especially human resource for health, drugs and other pharmaceutical supplies, skewed distribution of health resources which have continued to impact negatively on health equity. These have in the process eroded the positive gains that had earlier been realized in terms of health outcomes. Of particular concerns are issues relating to stock outs of 
drugs, dilapidated health infrastructure, significant gaps in health resources including workers, equipment and commodities, and non-prioritized health investments such as the recent purchase of health containers meant for the poor and other vulnerable groups. Thus, despite the positive gains in terms of health indicators, Kenya's progress towards universal coverage exhibit matters of concern like other developing countries.

The challenges continue to worry many stakeholders since this is likely to affect the realization of Sustainable Development goals (SDGs). This is happening despite the provisions of the constitution that one, health is the fundamental duty of the state and every state organ to respect, protect, promote and fulfill the rights and fundamental freedoms of Bill of Rights. Two, every person has a right to the highest attainable standards of health, which includes the right to health care services, including reproductive health; and three, consumers have a right to goods and services of reasonable quality. To date however, there are no supportive Acts of Parliament that define implementation of these provisions. Enforcement of this right is task that squarely lie with the state and its respective organs to ensure that quality is standardized with respect to infrastructure, human resource, skills and supplies. Further, the enforcement of the right to quality health requires the government commitment to meet the financial obligation. Universal health coverage that the government is committed to must be well thought out and efficiently rolled out for it to be successful. It s thus upon the state to take up the responsibility in ensuring constitutional right is upheld and at all times as mandated in the constitution. This requires the enactment of necessary legislations starting with the Health Bill, civic education to all. The doctors' strike now in its third month provides an opportunity to open the discussion and commitment to take the necessary measures to enhance equity in the state of health.

\section{REFERENCES}

[1] Bernard F. C., (2012) "Decentralisation and Governance in the Ghana Health Sector",. The International Bank for Reconstruction, The World Bank, Washington

[2] Bultman, Jan (2014): Kenya. Health Financing Strategy Development. Options for Reform and choices to be made

[3] GoK (1999), Kenya National Health Sector Strategic Plan (KHSSP) I, Government Printers, Nairobi

[4] GoK (2007), Kenya Vision 2030, Government Printers, Nairobi

[5] GoK (2010a), The Constitution, Government Printers, Nairobi

[6] GoK (2012) Kenya National Health Sector Strategic Plan (KHSSP) III, Government Printers, Nairobi

[7] GoK (2014) Kenya Demographic Health Survey, Government Printers, Nairobi

[8] GoK (1994), Kenya Health Policy Framework, Government Printers, Nairobi

[9] GoK (2015), Kenya Health Bill 2015, Government Printers, Nairobi

[10] GoK/Health Systems 2020 Project (2009), Kenya National Health Accounts 2005/2006. Bethesda, MD: Health Systems 20/20 project, Abt Associates Inc

[11] Government of Kenya. (2010b). Kenya Health Situation Analysis, Trends and Distribution, 1994 - 2010 and Projections to 2030. Ministry of Medical Services and Ministry of Public Health and Sanitation.

[12] Harmonization for Health in Africa (2010) Improving Financial Access to Health Services in West and Central Africa: Report of the Technical Workshop to Share Experiences in the Development and Implementation of Policies - Dakar, Senegal, HHA, Dakar.

[13] KPMG (2015), Devolution of Healthcare Services in Kenya, Meessen B, Kouanda S, Musango L et al. (2011) Communities of practice: the missing link for knowledge management on implementation issues in low-income countries? Tropical Medicine \& International Health Vol 16: PP 1007-14.

[14] Meessen, B. David H., Mathieu N., Valery R., Abdelmajid T., Christine K.T., Lucy G., (2009), Health Policy and Planning Vol. 26; 2: PP 16-29.

[15] Ministry of Health (1999). National Health Sector Strategic Plan: 1999- 2004 (NHSSP). Nairobi: Ministry of Health, Health Sector Reform Secretariat

[16] Ministry of Health (2003), Kenya Household Health Expenditure and Utilization Survey. Nairobi: Ministry of Health; 2003.

[17] Ministry of Health (2007). Facts and Figures at a Glance: Health and Health-related Indicators 2006. Nairobi: Division of Policy and Planning, Ministry of Health

[18] Ministry of Health (2008): Sector Plan for Health 2008-2012. Ministry of Medical Services and Ministry of Public Health and Sanitation

[19] Ministry of Health (2010), Draft Health Financing Strategy of 2010Ministry of Health (2012) draft Health Policy Framework, 2012 - 2030, unpublished reports

[20] Ministry of Health, (2014) Towards Universal Health Coverage: The Kenya Health Strategic and Investment Plan, 2014 - 2018 / Human Resources for Health Norms and Standards Guidelines for the Health Sector, 
[21] Ministry of Medical Services (2012), Sessional paper no. 7 of 2012 on The Policy on Universal Health care Coverage in Kenya

[22] MoH (2014) Kenya Health Sector Reforms and Roadmap Towards Universal Health CoverageMoH (2015) Kenya Demographic and Health Survey (KDHS), Key Health Indicators Musyimi et al. (2012) Strengthening Health Service Delivery, Report of the Taskforce constituted to address Health Sector issues raised by the Kenya Medical Practitioners, Pharmacists and Dentists Union

[23] National Hospital Insurance Fund (2005), NHIF accreditation manual. National hospital insurance fund, Government Printer

[24] NHIF (2015), Contribution and deductions rates. [http://www.nhif.or.ke/healthinsurance/ ratesNyamwaya D., (2011) Draft Report: Situational Analysis of Health promotion in Kenya, MOHS

[25] Okech C. T., \& Lelegwe L.S., (2016), Analysis of Universal Health Coverage and Equity on Health Care in Kenya, Global Journal of Health Science; Vol. 8, No. 7;

[26] Okech C.T., (2014) Review of On-going Efforts in the Implementation of the Health Financing Functions and Proposal for Feasible Financing Options, Report submitted to Future GroupP4H (2014), Options for Kenya's health financing system A P4H Policy Brief,

[27] Population Reference Bureau (PRB) (2015), World Population Highlights, Washington DC

[28] Sohnen E, Lara G., Alec H. Omolo J., and Karau J., (2015), Kenya Health Sector Labor Market Assessment, Draft

[29] Transparency International - Kenya. (2011). The Kenya Health Sector Integrity Study Report.Wamai R.G. (2004) Recent International Trends in NGO Health System Development, Organization, and Collaborations with Government in Transforming Health Care Systems: The Case of Finland and Kenya. Department of Social Policy/Institute of Development Studies. Finland: University of Helsinki; 2004 Jun.

[30] Witter S, Khadka S, Nath H, Tiwari S. (2011). The national free delivery policy in Nepal: early evidence of its effects on health facilities. Health Policy and Planning Vol 26: 2; PP 84-91.

[31] World Bank (2012) World Bank Fiscal Decentralisation Knowledge Programme Team. Devolution Without Disruption: Pathways to a Successful New Kenya

[32] World Health Organisation. (August, 2010) Global Atlas of Health Work Force.

[33] World Health Organization. (2010). Health Systems Financing: The Path to Universal Coverage. Geneva: World Health Organization; 2010.

[34] World Health Organisation. (May, 2012) Country Health Profile

Appendices

Table A1: Medical Personnel by Region and Ownership

\begin{tabular}{|c|c|c|c|c|c|c|c|c|c|c|c|c|c|c|c|c|c|c|c|}
\hline \multirow[t]{2}{*}{ Description } & \multicolumn{2}{|c|}{ Nairobi } & \multicolumn{2}{|c|}{ Eastern } & \multicolumn{2}{|c|}{$\begin{array}{l}\text { Rift } \\
\text { Valley }\end{array}$} & \multicolumn{2}{|c|}{ Nyanza } & \multicolumn{2}{|c|}{ Western } & \multicolumn{2}{|c|}{ Coast } & \multicolumn{2}{|c|}{$\begin{array}{l}\text { North } \\
\text { Eastern }\end{array}$} & \multicolumn{2}{|c|}{ Central } & \multicolumn{3}{|c|}{ National } \\
\hline & $\begin{array}{l}\text { GO } \\
\mathrm{K}\end{array}$ & $\begin{array}{l}\mathrm{F} \\
\mathrm{B} \\
\mathrm{O} / \\
\mathrm{N} \\
\mathrm{G} \\
\mathrm{O}\end{array}$ & $\begin{array}{l}\mathrm{O} \\
\mathrm{K}\end{array}$ & $\begin{array}{l}\mathrm{F} \\
\mathrm{B} \\
\mathrm{O} / \\
\mathrm{N} \\
\mathrm{G} \\
\mathrm{O}\end{array}$ & $\begin{array}{l}\mathrm{G} \\
\mathrm{O} \\
\mathrm{K}\end{array}$ & $\begin{array}{l}\mathrm{F} \\
\mathrm{B} \\
\mathrm{O} / \\
\mathrm{N} \\
\mathrm{G} \\
\mathrm{O}\end{array}$ & $\begin{array}{l}\mathrm{O} \\
\mathrm{K}\end{array}$ & $\begin{array}{l}\mathrm{F} \\
\mathrm{B} \\
\mathrm{O} / \\
\mathrm{N} \\
\mathrm{G}\end{array}$ & $\begin{array}{l}\mathrm{O} \\
\mathrm{K}\end{array}$ & $\begin{array}{l}\mathrm{F} \\
\mathrm{B} \\
\mathrm{O} / \\
\mathrm{N} \\
\mathrm{G}\end{array}$ & $\begin{array}{l}\text { GO } \\
\mathrm{K}\end{array}$ & $\begin{array}{l}\mathrm{F} \\
\mathrm{B} \\
\mathrm{O} / \\
\mathrm{N} \\
\mathrm{G} \\
\mathrm{O}\end{array}$ & $\begin{array}{l}\mathrm{G} \\
\mathrm{O} \\
\mathrm{K}\end{array}$ & $\begin{array}{l}\mathrm{F} \\
\mathrm{B} \\
\mathrm{O} / \\
\mathrm{N} \\
\mathrm{G} \\
\mathrm{O}\end{array}$ & $\begin{array}{l}\mathrm{G} \\
\mathrm{O} \\
\mathrm{K}\end{array}$ & $\begin{array}{l}\mathrm{FB} \\
\mathrm{O} / \mathrm{N} \\
\mathrm{GO}\end{array}$ & $\begin{array}{l}\mathrm{GO} \\
\mathrm{K}\end{array}$ & $\begin{array}{l}\mathrm{F} \\
\mathrm{B} \\
\mathrm{O}\end{array}$ & $\begin{array}{l}\text { TOTA } \\
\mathrm{L}\end{array}$ \\
\hline $\begin{array}{l}\text { Consultants } \\
\text { (MD) }\end{array}$ & 159 & $\begin{array}{l}15 \\
4\end{array}$ & 5 & 4 & $\begin{array}{l}10 \\
9\end{array}$ & 15 & 38 & 18 & 24 & 8 & 40 & 3 & 7 & 0 & 55 & 49 & 477 & $\begin{array}{l}25 \\
1\end{array}$ & 728 \\
\hline $\begin{array}{l}\text { Dental } \\
\text { Technologists }\end{array}$ & 15 & 16 & 5 & 2 & 35 & 2 & 7 & 3 & 7 & 1 & 12 & 3 & 3 & 0 & 16 & 7 & 100 & 34 & 134 \\
\hline $\begin{array}{l}\text { Community } \\
\text { Oral Health } \\
\text { officers }\end{array}$ & 7 & 0 & 1 & 1 & 42 & 4 & 10 & 1 & 10 & 1 & 15 & 4 & 0 & 0 & 12 & 8 & 115 & 19 & 134 \\
\hline $\begin{array}{l}\text { Clinical } \\
\text { officers } \\
\text { (specs) }\end{array}$ & 92 & 75 & 4 & 3 & $\begin{array}{l}34 \\
7\end{array}$ & 11 & 68 & 28 & 75 & 6 & 82 & 13 & 14 & 3 & $\begin{array}{l}10 \\
0\end{array}$ & 26 & 921 & $\begin{array}{l}16 \\
5\end{array}$ & 1086 \\
\hline
\end{tabular}




\begin{tabular}{|c|c|c|c|c|c|c|c|c|c|c|c|c|c|c|c|c|c|c|c|}
\hline $\begin{array}{l}\text { Clinical } \\
\text { officers (Gen) }\end{array}$ & 87 & 50 & $\begin{array}{l}1 \\
3 \\
0\end{array}$ & 23 & $\begin{array}{l}33 \\
3\end{array}$ & 95 & $\begin{array}{l}23 \\
7\end{array}$ & 70 & $\begin{array}{l}10 \\
2\end{array}$ & 47 & 157 & 40 & 50 & 4 & $\begin{array}{l}15 \\
0\end{array}$ & 60 & $\begin{array}{l}124 \\
6\end{array}$ & $\begin{array}{l}38 \\
9\end{array}$ & 1635 \\
\hline $\begin{array}{l}\text { BSN Nursing } \\
\text { officers }\end{array}$ & $\begin{array}{l}108 \\
7\end{array}$ & $\begin{array}{l}10 \\
78\end{array}$ & $\begin{array}{l}2 \\
0\end{array}$ & 7 & $\begin{array}{l}40 \\
6\end{array}$ & 48 & $\begin{array}{l}13 \\
0\end{array}$ & 16 & 2 & 2 & 205 & 28 & 1 & 0 & $\begin{array}{l}22 \\
0\end{array}$ & 94 & $\begin{array}{l}207 \\
1\end{array}$ & $\begin{array}{l}12 \\
73\end{array}$ & 3344 \\
\hline $\begin{array}{l}\text { Registered } \\
\text { Nurses }\end{array}$ & 924 & $\begin{array}{l}80 \\
7\end{array}$ & $\begin{array}{l}4 \\
0 \\
5\end{array}$ & $\begin{array}{l}10 \\
8\end{array}$ & $\begin{array}{l}12 \\
07\end{array}$ & $\begin{array}{l}31 \\
7\end{array}$ & $\begin{array}{l}76 \\
9\end{array}$ & $\begin{array}{l}26 \\
4\end{array}$ & $\begin{array}{l}39 \\
4\end{array}$ & $\begin{array}{l}11 \\
4\end{array}$ & 846 & 98 & $\begin{array}{l}16 \\
0\end{array}$ & 11 & $\begin{array}{l}39 \\
3\end{array}$ & 443 & $\begin{array}{l}509 \\
8\end{array}$ & $\begin{array}{l}21 \\
62\end{array}$ & 7260 \\
\hline $\begin{array}{l}\text { Enrolled } \\
\text { Nurses }\end{array}$ & 576 & $\begin{array}{l}40 \\
2\end{array}$ & 1 & $\begin{array}{l}48 \\
2\end{array}$ & $\begin{array}{l}24 \\
20\end{array}$ & $\begin{array}{l}31 \\
3\end{array}$ & $\begin{array}{l}13 \\
47\end{array}$ & $\begin{array}{l}38 \\
7\end{array}$ & $\begin{array}{l}12 \\
50\end{array}$ & $\begin{array}{l}16 \\
6\end{array}$ & 926 & $\begin{array}{l}28 \\
6\end{array}$ & $\begin{array}{l}31 \\
1\end{array}$ & 8 & $\begin{array}{l}17 \\
63\end{array}$ & 353 & $\begin{array}{l}990 \\
6\end{array}$ & $\begin{array}{l}23 \\
97\end{array}$ & 12303 \\
\hline $\begin{array}{l}\text { Public Health } \\
\text { Officers }\end{array}$ & 91 & 55 & $\begin{array}{l}1 \\
9\end{array}$ & 1 & $\begin{array}{l}61 \\
2\end{array}$ & 9 & $\begin{array}{l}14 \\
8\end{array}$ & 29 & $\begin{array}{l}12 \\
5\end{array}$ & 4 & 170 & 68 & 47 & 0 & $\begin{array}{l}16 \\
0\end{array}$ & 6 & $\begin{array}{l}154 \\
6\end{array}$ & $\begin{array}{l}17 \\
2\end{array}$ & 1718 \\
\hline $\begin{array}{l}\text { Public Health } \\
\text { Otechnicians }\end{array}$ & 37 & 20 & $\begin{array}{l}3 \\
2\end{array}$ & 6 & $\begin{array}{l}66 \\
5\end{array}$ & 10 & $\begin{array}{l}17 \\
4\end{array}$ & 15 & $\begin{array}{l}14 \\
8\end{array}$ & 3 & 101 & 3 & 49 & 0 & $\begin{array}{l}26 \\
4\end{array}$ & 2 & $\begin{array}{l}175 \\
8\end{array}$ & 59 & 1817 \\
\hline Pharmacists & 30 & 29 & 4 & 2 & 55 & 1 & 23 & 5 & 34 & 1 & 49 & 4 & 4 & 0 & 39 & 10 & 277 & 52 & 329 \\
\hline $\begin{array}{l}\text { Pharm. } \\
\text { Technologists }\end{array}$ & 54 & 60 & $\begin{array}{l}5 \\
1\end{array}$ & 10 & $\begin{array}{l}11 \\
1\end{array}$ & 20 & 14 & 27 & 21 & 11 & 31 & 9 & 12 & 1 & 17 & 56 & 311 & $\begin{array}{l}19 \\
4\end{array}$ & 505 \\
\hline $\begin{array}{l}\text { Lab. } \\
\text { Technologists }\end{array}$ & 154 & $\begin{array}{l}14 \\
6\end{array}$ & $\begin{array}{l}1 \\
8\end{array}$ & 18 & $\begin{array}{l}31 \\
6\end{array}$ & 54 & $\begin{array}{l}14 \\
8\end{array}$ & 73 & $\begin{array}{l}12 \\
1\end{array}$ & 19 & 152 & 42 & 34 & 2 & $\begin{array}{l}13 \\
4\end{array}$ & 53 & $\begin{array}{l}123 \\
9\end{array}$ & $\begin{array}{l}40 \\
7\end{array}$ & 1646 \\
\hline $\begin{array}{l}\text { Lab } \\
\text { Technicicans }\end{array}$ & 58 & 56 & $\begin{array}{l}6 \\
8\end{array}$ & $\begin{array}{l}10 \\
5\end{array}$ & $\begin{array}{l}17 \\
7\end{array}$ & 39 & 90 & 71 & 73 & 27 & 106 & 38 & 9 & 4 & $\begin{array}{l}15 \\
2\end{array}$ & 72 & 733 & $\begin{array}{l}41 \\
2\end{array}$ & 1145 \\
\hline $\begin{array}{l}\text { Ortho. } \\
\text { Technologists }\end{array}$ & 15 & 10 & $\begin{array}{l}3 \\
3\end{array}$ & 1 & 26 & 0 & 11 & 9 & 10 & 3 & 15 & 9 & 2 & 0 & 16 & 8 & 128 & 40 & 168 \\
\hline Nutritionists & 79 & 54 & 6 & 2 & $\begin{array}{l}14 \\
4\end{array}$ & 12 & 28 & 25 & 27 & 3 & 46 & 5 & 14 & 2 & 50 & 7 & 153 & $\begin{array}{l}11 \\
0\end{array}$ & 563 \\
\hline $\begin{array}{l}\text { Radiographer } \\
\mathrm{s}\end{array}$ & 63 & 56 & $\begin{array}{l}4 \\
7\end{array}$ & 3 & 95 & 6 & 34 & 15 & 24 & 1 & 70 & 2 & 8 & 0 & 36 & 14 & 377 & 97 & 474 \\
\hline $\begin{array}{l}\text { Physiotherapi } \\
\text { sts }\end{array}$ & 83 & 64 & 8 & 3 & $\begin{array}{l}10 \\
5\end{array}$ & 10 & 54 & 8 & 31 & 3 & 88 & 6 & 6 & 0 & 59 & 17 & 512 & $\begin{array}{l}11 \\
1\end{array}$ & 623 \\
\hline $\begin{array}{l}\text { Occupational } \\
\text { therapists }\end{array}$ & 45 & 38 & $\begin{array}{l}4 \\
2\end{array}$ & 1 & 75 & 1 & 20 & 1 & 22 & 0 & 36 & 3 & 3 & 0 & 36 & 8 & 279 & 52 & 331 \\
\hline $\begin{array}{l}\text { Plaster } \\
\text { Technicians }\end{array}$ & 26 & 14 & $\begin{array}{l}1 \\
4\end{array}$ & 1 & 68 & 2 & 10 & 2 & 11 & 1 & 18 & 3 & 7 & 0 & 38 & 5 & 192 & 28 & 220 \\
\hline $\begin{array}{l}\text { Health } \\
\text { records \& } \\
\text { information } \\
\text { officers }\end{array}$ & 69 & 64 & $\begin{array}{l}1 \\
3 \\
5\end{array}$ & 0 & 88 & 5 & 24 & 8 & 15 & 1 & 44 & 5 & 4 & 1 & 30 & 7 & 409 & 91 & 500 \\
\hline $\begin{array}{l}\text { Health } \\
\text { records \& } \\
\text { information } \\
\text { technicians }\end{array}$ & 51 & 49 & $\begin{array}{l}6 \\
6\end{array}$ & 2 & 64 & 4 & 18 & 6 & 18 & 6 & 62 & 15 & 4 & 0 & 60 & 22 & 343 & $\begin{array}{l}10 \\
4\end{array}$ & 447 \\
\hline $\begin{array}{l}\text { Trained } \\
\text { Community } \\
\text { health }\end{array}$ & 256 & $\begin{array}{l}55 \\
0\end{array}$ & $\begin{array}{l}4 \\
6\end{array}$ & 0 & $\begin{array}{l}34 \\
22\end{array}$ & $\begin{array}{l}22 \\
4\end{array}$ & $\begin{array}{l}25 \\
06\end{array}$ & 15 & $\begin{array}{l}36 \\
50\end{array}$ & $\begin{array}{l}28 \\
9\end{array}$ & $\begin{array}{l}105 \\
4\end{array}$ & 13 & $\begin{array}{l}33 \\
4\end{array}$ & 75 & $\begin{array}{l}29 \\
66\end{array}$ & 223 & $\begin{array}{l}166 \\
49\end{array}$ & $\begin{array}{l}13 \\
89\end{array}$ & 18038 \\
\hline
\end{tabular}




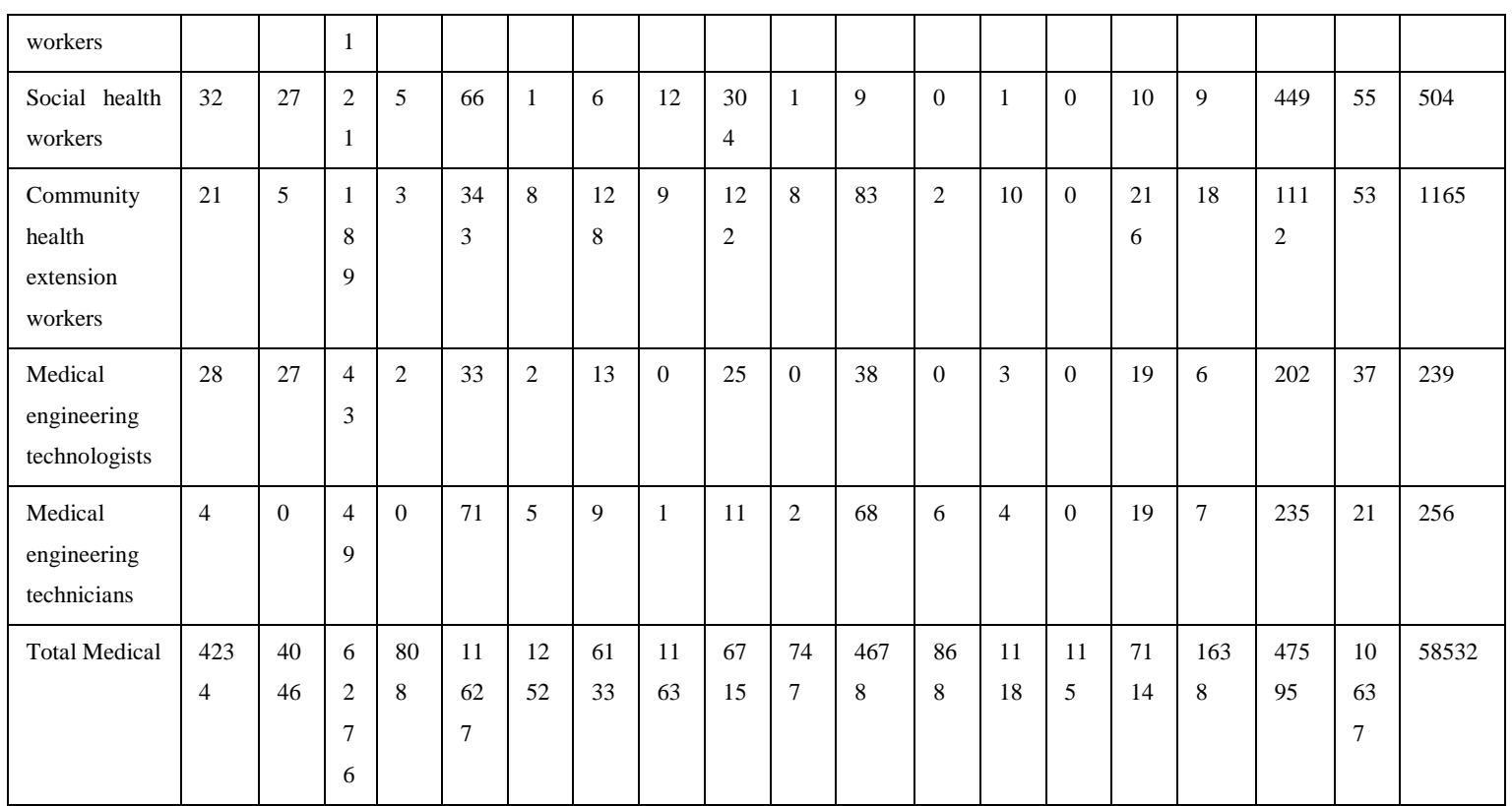

Appendix Two: Comparison of Kenya's Health Indicators and Global and MDGs' target

\section{KENYA}

Total fertility rate

Contraceptive prevalence rate for married women $\quad 53 \%$

Contraceptive prevalence rate for unmarried women $\quad 61 \%$

Infant mortality rate - deaths per 1,000 live births $\quad 39$

Under-five mortality rate - deaths per 1,000 live births. 52

Maternal deaths per 100,000 live births

Life expectancy

Delivered in a health facility

Full vaccination

Stunted growth (too short for age) - \% under 5 years

$26 \%$

Use of ITN - \%

HIV testing - \% women

HIV testing - \% men

Neonatal mortality -- per 1,000 live births

Access to delivery by skilled health workers - \%

Post natal care - \%-

Nutrition status-\% --- under 5 years

Wasted

\section{Underweight}

Overweight

Geographical access

Malaria Prevalence ---

HIV prevalence --
$4 \%$

GLOBAL

MDGs

3.9 